\title{
68. The Floating Zone Refining of Iron
}

\author{
By Takayuki ŌoKa, Hiroshi Mimura, Seinosuke Yano, \\ and Seiichi SoEdA \\ Tokyo Research Institute, Yawata Iron and Steel Co., Ltd. \\ (Comm. by San-ichiro Mizushima, M.J.A., May 11, 1963)
}

I. Introduction. In recent years, several studies have been published on zone refining of iron. ${ }^{1-6)}$ Efficiency of the zone refining has been expressed by the distribution coefficient $k$. The values of $k$ have been determined for $\mathrm{P}, \mathrm{O}, \mathrm{C}, \mathrm{B}$ and $\mathrm{S}$ in iron. The present experiment was carried out to see, if the refining efficiency for $\mathrm{Ni}$, $\mathrm{Mn}, \mathrm{C}, \mathrm{S}$ and $\mathrm{O}$ can be explained by the existing theory. The floating zone melting method was employed to avoid contamination from the crucible. It was found that the solute distribution for $\mathrm{Ni}$ is well explained by the available theoretical expression including only the effect of segregation. However, in order to explain the solute distribution for $\mathrm{Mn}, \mathrm{C}, \mathrm{S}$ and $\mathrm{O}$, it has been found necessary to take account of the evaporation of the solute. There still remains some disagreement as to the solute distribution of $\mathrm{C}$ and $\mathrm{S}$ at slow travelling rates, and that of $O$ at any rate. It is suggested in this report that the diffusion in the solid phase just adjacent to the molten zone is responsible for this disagreement. The experimental values are well explained by including this effect.

II. Apparatus and material. The present apparatus is quite similar to that used by Rutherford and Smith. ${ }^{1)}$ Chemical analysis of original samples used was made in our laboratory and the result is shown in Table I.

Table I. Chemical composition of original materials

\begin{tabular}{|c|c|c|c|c|c|c|c|c|c|c|}
\hline \multirow{2}{*}{$\begin{array}{l}\text { Element } \\
\text { Sample }\end{array}$} & \multicolumn{8}{|c|}{$\%$} & \multirow{2}{*}{ Note } & \multirow{2}{*}{$\begin{array}{l}\text { Noticed } \\
\text { element }\end{array}$} \\
\hline & $\mathrm{C}$ & S & $\mathrm{Mn}$ & $\mathrm{P}$ & $\mathrm{Si}$ & $\mathrm{Ni}$ & 0 & $\mathrm{~N}$ & & \\
\hline $2 \mathrm{~S}$ & 0.16 & 0.135 & 0.82 & 0.015 & 0.15 & - & - & - & Free cutting steel & S \\
\hline PU & 0.067 & 0.003 & 0.005 & 0.0005 & 5.020 & - & 0.007 & - & $\begin{array}{l}\text { Puron (Westinghouse } \\
\text { Co., Ltd.) }\end{array}$ & $\mathrm{C}$ \\
\hline $\mathrm{FV}$ & .003 & 0.003 & 005 & 50.003 & 0.0070 & 0.028 & 0.0242 & 0.0023 & $\begin{array}{c}\text { Ferrovac E } \\
\text { (Crucible Co., Ltd.) }\end{array}$ & $\mathrm{Ni}$ \\
\hline $\mathrm{FV}-7-\mathrm{H}$ & 0.004 & 0.002 & 0.000 & 0.002 & 0.006 & - & 0.0191 & - & $\underset{(}{\text { Ferrovac }} \underset{\mathrm{E}}{\prime \prime}$ & 0 \\
\hline $\mathrm{MN}-3-\mathrm{H}$ & 0.016 & 0.006 & 0.10 & 0.004 & 0.008 & - & 0.05630 & 0.0011 & Vacuum melted iron & $\mathrm{Mn}$ \\
\hline
\end{tabular}

III. Result and dicussion. 1. The effect of segregation. According to the custom theory of zone refining the concentration of the solute at the distance $x$ from the starting end for the $n$-th pass 
$C_{n}(x)$ is given by the following equation:

$$
C_{n}(x)=\frac{k}{l}\left[\int_{0}^{x+l} C_{n-1}(x) d x-\int_{0}^{x} C_{n}(x) d x\right],
$$

where $k$ is the effective distribution coefficient, and $l$ the zone length. The solution of equation (1) is given by Lord in the case of a sample of semi-infinite length as follows: ${ }^{7)}$

where

$$
\begin{aligned}
& C_{n}(x \cdot k)=C_{0}\left\{1-(1-k) \exp (-k a)\left[n-\sum_{t=1}^{n-1} \sum_{s=1}^{t} k^{s-1} \cdot \exp (-s k) \cdot\right.\right. \\
&\left.\left.\sum_{r=0}^{s-1} f_{r}(s) \cdot a^{r} \cdot(r+1-k a)\right]\right\},
\end{aligned}
$$

$$
\begin{aligned}
a & =x / l, \\
f_{r}(s) & =s^{s-r-2} /(s-r-1) ! \cdot r !
\end{aligned}
$$

and $C_{0}$ is the original concentration of the solute.

2. Result of measurement. For the purpose of knowing the efficiency of removing the impurities in iron, we studied the distribution of solutes which have representative distribution coefficents such as $\mathrm{Ni}, \mathrm{Mn}, \mathrm{C}, \mathrm{S}$ and $\mathrm{O}$. The solute distribution after zone refining is determined from chemical analysis. The results are shown in Figs, 1-5. The abscissa shows $x / L$, the ordinate $C(x) / C_{0}$, where $L$ designates the whole length of the zone refined region, $x$ the distance measured from the starting end, $C(x)$ the solute concentration at distance $x$ and $C_{0}$ the original concentration. The results are summarized as follows. The distribution of $\mathrm{Ni}$ follows the usal theoretical solute distribution. The distribution of $\mathrm{O}$ and $\mathrm{Mn}$ is quite different from that of $\mathrm{Ni}, \mathrm{C}$ and $\mathrm{S}$ in such a way that firstly, $C(x)$ decreases as $x$ increases, secondly, $C(x)$ at dirty end decreases as travelling rate decreases.

3. Theoretical treatment taking account of vaporization. The material balance of a solute suggests that the solute is vaporized during the passage of the zone. For the sake of simplicity, the decrease of the solute due to vaporization is assumed to be proportional to the concentration of the solute, so that we have the following equation.

$$
d C / d t=-\kappa_{v} C
$$

The change of the solute concentration, during the advance of the zone by $d x$ is given by

$$
d C=-\left(\kappa_{v} C / f\right) d x
$$

Adding this term to equation (1), we obtain

$$
l d C_{n}(x)=\left[k C_{n-1}(x+l)-k C_{n}(x)-\kappa_{v} l C_{n}(x) / f\right] d x .
$$

Equation (5) was solved by Gould, ${ }^{8)}$ but his expression of $C_{n}(x)$ contains $C_{n-1}(x)$ and $n$-th power of integral operator. The simpler solution was made by us as follows: Let us put 
and

$$
k C_{n-1}(x) /\left(k+k_{v}\right)=C_{n-1}^{\prime}(x)
$$

then equation (5) is rewritten as

$$
C_{n}(x)=\left[\left(k+k_{v}\right) / l\right]\left[\int_{0}^{x+l} C_{n-1}^{\prime}(x) d x-\int_{0}^{x} C_{n}(x) d x\right] .
$$

Equation (7) has the same form as equation (1) if the solute concentration of the $(n-1)$-th pass is given by $C_{n-1}^{\prime}(x)$ and the distribution coefficient by $\left(k+k_{v}\right)$. Then the solution of equation (7) $C_{n}\left(x \cdot k \cdot k_{v}\right)$ is obtained as

$$
C_{n}\left(x \cdot k \cdot k_{v}\right)=\left(\frac{k}{k+k_{v}}\right)^{n} C_{n}\left(x \cdot k+k_{v}\right)
$$

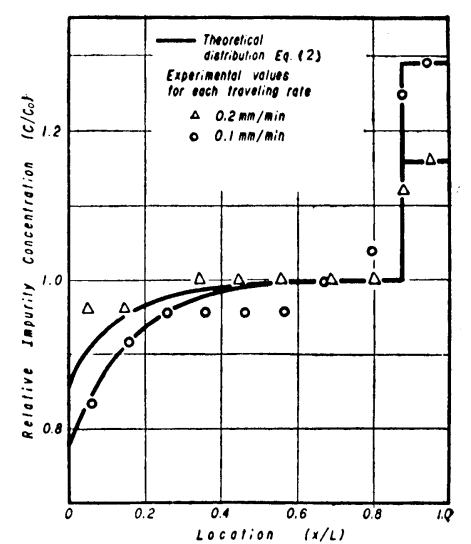

Fig. 1. Distribution of nickel in iron after one zone pass.

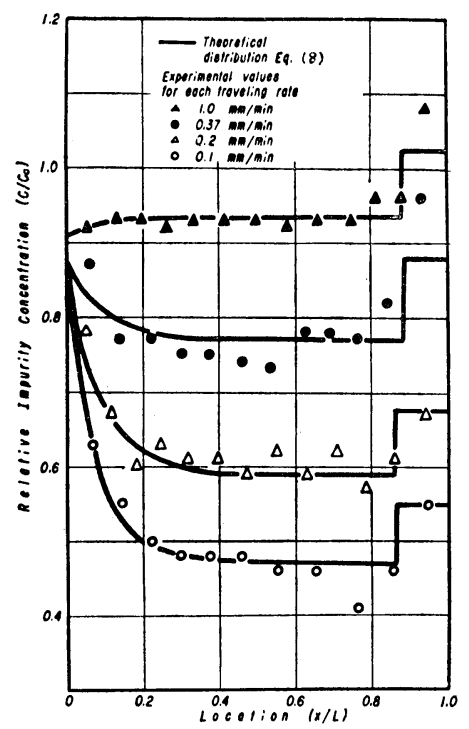

Fig. 2. Distribution of manganese in iron after one zone pass.

The theoretical curves in Figs 1-2 are calculated from equation (8). The values of $k$ are determined from the ratio of the concentration of the dirty end to that of the part just above it, and the values of $k_{v}$ are obtained from the values of $C_{0} \cdot k /\left(k+k_{v}\right)$ to which the concentration approaches for large $x$. The values of $k$ and $k_{v}$ are shown in Table II for the various travelling rates.

In this way, all data are explained satisfactorily except for $\mathrm{C}$ and $S$ in the case of the slow travelling rate and for $O$ at any rate. In these exceptional cases the experimental values deviate from the theoretical curve upward in the initial region.

4. Effect of diffusion in the solid phase. If there is appreciable diffusion in the solid phase, the solute in the solid phase tends to 
Table II. Values of $k$ and $k_{v}$ for each solute element

\begin{tabular}{|c|c|c|c|c|c|c|}
\hline Travelling rate & ent & $\mathbf{S}$ & $\mathrm{C}$ & $\mathrm{Mn}$ & $\mathrm{Ni}$ & 0 \\
\hline $0.1 \mathrm{~mm} / \mathrm{min}$ & $\begin{array}{l}k \\
k_{v}\end{array}$ & $\begin{array}{l}0.062 \\
0.11\end{array}$ & $\begin{array}{l}0.16 \\
0.064\end{array}$ & $\begin{array}{l}0.86 \\
0.96\end{array}$ & $\begin{array}{l}0.77 \\
0.0\end{array}$ & \\
\hline 0.2 & $\begin{array}{l}k \\
k_{v}\end{array}$ & & & $\begin{array}{l}0.87 \\
0.60\end{array}$ & $\begin{array}{l}0.86 \\
0.0\end{array}$ & $\begin{array}{l}0.093 \\
0.28\end{array}$ \\
\hline 0.37 & $\begin{array}{l}k \\
k_{v}\end{array}$ & $\begin{array}{l}0.31 \\
0.064\end{array}$ & $\begin{array}{l}0.28 \\
0.031\end{array}$ & $\begin{array}{l}0.88 \\
0.26\end{array}$ & $\begin{array}{l}0.90 \\
0.0\end{array}$ & $\begin{array}{l}0.14 \\
0.14\end{array}$ \\
\hline 1.0 & $\begin{array}{l}k \\
k_{v}\end{array}$ & $\begin{array}{l}0.4 \\
0.005\end{array}$ & $\begin{array}{l}0.45 \\
0.014\end{array}$ & $\begin{array}{l}0.91 \\
0.063\end{array}$ & $\begin{array}{l}0.96 \\
0.0\end{array}$ & \\
\hline
\end{tabular}

flow into the molten zone at the initial stage of refining due to the difference of solubility. As a simple approximation, we assume that the initial concentration of the zone increases by factor $\alpha$ and the refining process is governed by equation (7).

Then, solution $C_{n}\left(x \cdot k \cdot k_{v} \cdot \alpha\right)$ is obtained as $C_{n}\left(x \cdot k \cdot k_{v} \cdot \alpha\right)=C_{n}\left(x \cdot k \cdot k_{v}\right)+k(1-\alpha) /\left\{1-\left(k+k_{v}\right)\right\} \cdot$

$$
\sum_{m=1}^{n} \frac{C_{n-m}^{*}\left(o \cdot k \cdot k_{v} \cdot \alpha\right)}{C_{0}}\left\{\frac{k+k_{v}}{k} C_{m}\left(x \cdot k \cdot k_{v}\right)-C_{m-1}\left(x \cdot k \cdot k_{v}\right)\right\},
$$

where

$$
C_{m}^{*}\left(o \cdot k \cdot k_{v} \cdot \alpha\right)=\frac{1}{l} \int_{0}^{l} C_{m}\left(x \cdot k \cdot k_{v} \cdot \alpha\right) d x .
$$

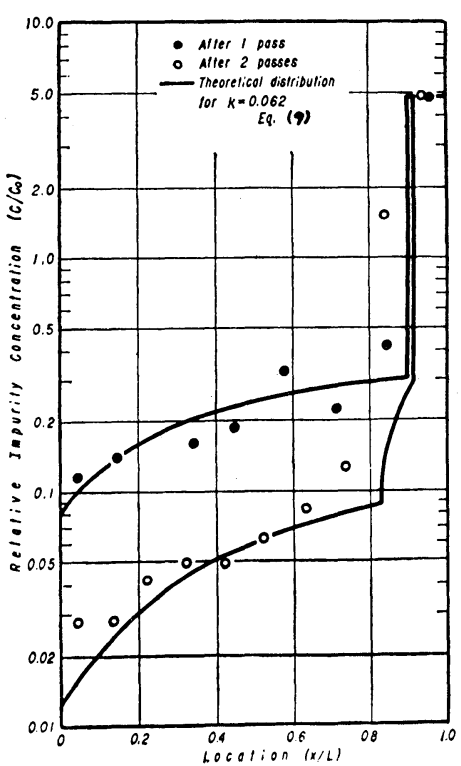

Fig. 3. Distribution of sulfur in iron after zone refining at the constant travelling rate, $0.1 \mathrm{~mm} / \mathrm{min}$. 


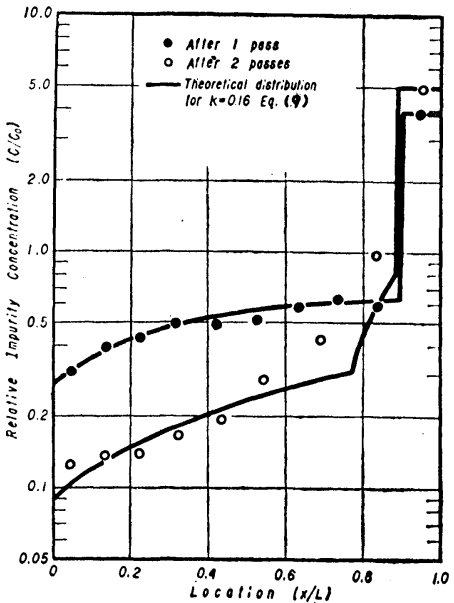

Fig. 4. Distribution of carbon in iron after zone refining at the constant travelling rate, $0.1 \mathrm{~mm} / \mathrm{min}$.

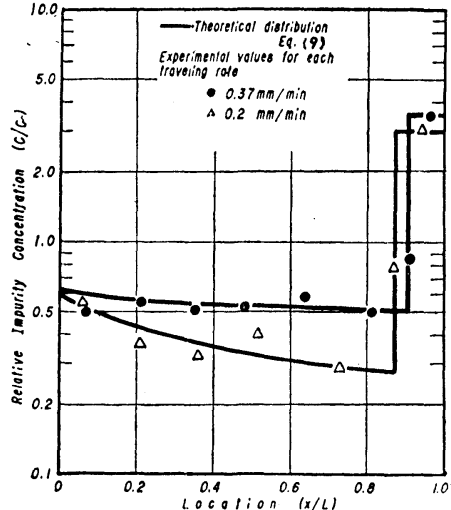

Fig. 5. Distribution of oxygen in iron after one zone pass.

$\alpha$ is determined by the ratio of $C_{1}^{*}\left(o \cdot k \cdot k_{v} \cdot \alpha\right)$ or the concentration of the initial part of the first pass to $C_{0}$. The theoretical curves in Figs. 3-5 are drawn using equation (9). The agreement between the theoretical and experimental values are good as seen from Figs. 3-5. In order to show that the diffusion in the solid phase increases the concentration of the zone at the starting end, the molten zone was kept stationary. As time passes the concentration of the solute in the molten zone increases and that of the solid zone adjacent to the molten zone decreases for $\mathrm{C}, \mathrm{S}$ and $\mathrm{O}$. As shown in Table III this tendency is most clearly seen for 0 . The concentration of the molten zone decreases for $\mathrm{Mn}$ and remains constant for $\mathrm{Ni}$.

Table III. Change of the concentration in the stationary melting

\begin{tabular}{|c|c|c|c|c|c|c|c|c|c|c|c|c|c|}
\hline \multicolumn{2}{|c|}{ Melting time (min) } & \multicolumn{3}{|c|}{1} & \multicolumn{3}{|c|}{6} & \multicolumn{3}{|c|}{28} & \multicolumn{3}{|c|}{60} \\
\hline Element & Original & A & B & $\mathrm{C}$ & A & B & C & A & B & C & A & B & C \\
\hline $\mathrm{s} \%$ & 0.142 & 0.120 & 0.138 & 0.140 & 0.134 & 0.140 & 0.132 & - & - & - & 0.108 & 0.1700 & 0.128 \\
\hline $\mathrm{C} \%$ & 0.067 & - & - & - & 0.062 & 0.065 & 0.049 & 0.059 & 0.097 & 0.063 & 0.045 & 0.0950 & 0.046 \\
\hline $0 \%$ & 0.072 & 0.050 & 0.116 & 0.052 & 0.063 & 0.140 & 0.074 & 0.051 & 0.108 & 0.023 & - & - & - \\
\hline $\begin{array}{ll}\mathrm{A}: & \mathrm{u} \\
\mathrm{B}: & \mathrm{r} \\
\mathrm{C}: & \mathrm{l}\end{array}$ & $\begin{array}{l}\text { upper solid } z \\
\text { molten zone. } \\
\text { lower solid } \mathrm{z}\end{array}$ & $\begin{array}{l}\text { zone a } \\
\text { zone a }\end{array}$ & $\begin{array}{l}\text { djacen } \\
\text { djacen }\end{array}$ & at to & $\begin{array}{l}\text { the } m \\
\text { the } m\end{array}$ & $\begin{array}{l}\text { nolten } \\
\text { nolten }\end{array}$ & $\begin{array}{l}\text { zone. } \\
\text { zone. }\end{array}$ & & & & & 20 & \\
\hline
\end{tabular}

IV. Conclusion. The present experiment on the floating zone refining of iron shows that in addition to the effect of segregation it is necessary to take account of the effect of the vaporization for 
the solute having high vapor pressure and the effect of the diffusion in the solid phase at the starting end. The theoretical expression was obtained by taking into account the above two effects. The agreement between theory and experiment was found to be satisfactory.

Acknowledgement. The authors wish to thank prof. S. Mizushima, Dr. T. Ikegami, and Dr. I. Ichishima for their interest in this research. Their thanks are also due to Prof. Z. Nishiyama and Prof. J. Takamura for their kind advices.

\section{References}

1) R. L. Smith and J. L. Rutherford: J. Metals, 9, 478, 857 (1957).

2) J. Talbot, P. Albert, and G. Chaudron: C. R. Seances Acad. Sci., 244, 1577 (1957).

3) W. A. Fischer, H. Spitzer, and M. Hishinuma: Arch Eisenhütt, 31, 365 (1960).

4) W. M. Williams, G. B. Craig, and W. C. Winegard: The Canadian Min. and Met., Bulletin for Jan. Montreal, 35 (1962).

5) E. B. Simonsen: J. Iron Steel Inst., 200, 193 (1962).

6) B. F. Oliver and A. J. Shafer: Trans. AIME, 218, 194 (1960).

7) N. W. Lord: J. Metals, 5, 1513 (1953).

8) J. R. Gould: Trans. AIME, 221, 1154 (1961). 